\title{
DOES YOUR DECISION-MAKING PROCESS PROTECT CUSTOMER VALUE?
}

\author{
Annett Schöttle ${ }^{1}$, Paz Arroyo², and Randi Christensen ${ }^{3}$
}

\begin{abstract}
Project teams make several decisions while designing and building construction projects impacting customer value. Most decisions are made without deliberate attention and based on the present individual's knowledge and experience in order to comply with an often unrealistic schedule. However, some decisions require deliberate considerations and cross-disciplinary review. What might seem insignificant for one discipline might have a huge impact in other parts of the scheme. We claim that values (beliefs) impact decisions and thereby the value (outcome). This paper explores how Choosing by Advantages (CBA) supports the making of deliberate decisions based on values and thereby helps to deliver value for a project. Based on a literature review, this paper will discuss procedures to make cross-disciplinary decisions using CBA principles to deliver value.
\end{abstract}

\section{KEYWORDS}

Choosing by Advantages (CBA), decision-making, value, values.

\section{INTRODUCTION}

Lean is about delivering value to the customer without waste. Yet, construction projects seldom define value before the start of design, and later value is inefficiently tested during construction. Value delivery is said to be poorly understood and conceptualized in the construction industry (Drevland and Klakegg 2019). Often only the outcome, which can be measured, is perceived as relevant or valuable in explicit decisions. Moreover, the connection between customer value and the purpose of the project usually gets lost during a highly fragmented and short-term oriented decision-making process. The value itself is interpreted and assumed by the project team without a clear understanding of the owner's business case or context. Consequently, decisions seem insignificant for some disciplines or parties and hence they make decisions without involving others, and the window for considering other options might have passed before it has been realized. Plus, owners often define value made by trial and error based on presented solutions and feedback. Moreover, it seems that the industry seldom separates cost from value. This leads to rework and conflicts in the process of design development. Often an assumed agreement on a design element is later changed due to lack of communication around the constraints

1 Senior Consultant, Refine Projects AG, Schelmenwasenstraße 34, 70567 Stuttgart, Germany, +4915156561529, annett.schoettle@,refine.team and Founder and Co-Director, CollabDecisions, www.collabdecisions.com, orcid.org/0000-0001-6001-7320

2 Quality Leader, DPR, San Francisco, CA, PazA@dpr.com, and Founder and Co-Director, CollabDecisions, www.collabdecisions.com, orcid.org/0000-0002-8098-8172

3 Associate Technical Director (Lean), COWI, RMCH@cowi.com and Founder and Co-Director, CollabDecisions, www.collabdecisions.com, orcid.org/0000-0002-3377-7057 
or the perceived value. Additionally, the decision-making process is not clearly set up from the beginning, so that it is not always clear when the client wants to be part of a decision, and neither the design team nor the owner takes ownership of the decision. This is a big issue, because decisions will not be made effectively and on time. Projects such as UCSF Mission Hall show that owners with a clearly defined value from the beginning of the project make design more efficient. Their Bridging Document defined the building outcome based on a clear project program, design criteria, and a comprehensive performance specification (Schöttle et al. 2015).

Therefore, this paper discusses the impact of values on decisions and how CBA can help in delivering value when making decisions.

\section{METHODOLOGY}

This paper explores different bodies of literature to answer the research question: How does Choosing by Advantages (CBA) support making deliberate decisions based on values and thereby help to deliver value for a project? Unclear use of terminology has often led to misunderstandings and probably waste in construction projects. Therefore, we first study the definitions of values, goals, criteria, and value delivery in the context of decision-making. Then we review two major strategies of value management to better understand value generation. Then we explain how CBA assesses the value within the decision-making process. Finally, we present a theoretical discussion on how CBA can support the decision-making process to deliver value by setting a framework for discussions in which customer values impact the value of the decision and thereby the project.

\section{VALUES, GOALS, CRITERIA, AND VALUE DELIVERY}

For many, the difference between value and values is the letter 's'. However, diving into this discussion, it shows that it is more complicated, which might explain why this conversation is so difficult. Value is "the outcome of an evaluative judgment" (Holbrook 1999, p. 8) and as a concept has always been part of the construction industry. But the term value seems to have different meanings in different situations and when using different tools and techniques (e.g., Drevland and Lohne 2015; Salvatierra-Garrido et al. 2010). Table 1 shows different definitions of value from the perspectives of the production system to society. Most definitions have in common that value depends on the participants involved in the value-generating process (e. g. Emmitt et al. 2005) and therefore are subjective and can change over time (Christoffersen 2003). For example, Drevland and Lohne (2015) demonstrate clearly that "value is guided by values" (p. 479) and is based on experience and depends on content and knowledge. This statement demonstrates the importance of language, as value is not the singular version of values. In accordance with the literature review of Schwartz and Bilsky (1987), values can be defined as (1) "concepts or beliefs, (2) about desirable end states or behaviors, (3) that transcend specific situations, (4) guide selection or evaluation of behavior and events, and (5) are ordered by relative importance" (p. 551). This definition goes hand in hand with Suhrs' (1999) definition that "values are defined as deeply-held beliefs about what is true and false, good vs. bad and right vs. wrong" (p. 178). Furthermore, various authors define resources or cost as value. In accordance with Suhr (1999), we define them based on the conditions as targets or constraints that restrict the decisions of a project team, because 
they have no value in themselves (Suhr 1999). Thus, we define values as beliefs and value as outcomes based on an evaluative judgment.

Table 1: Extract of value definitions

\begin{tabular}{|c|c|}
\hline Reference & Definition of Value \\
\hline $\begin{array}{l}\text { Johnson and } \\
\text { Kaplan (1987) }\end{array}$ & $\begin{array}{l}\text { "[V]alue of any commodity, service, or condition, utilized in production, } \\
\text { passes over into the object or product for which the original item was } \\
\text { expended and attaches to the result, giving it its value" (pp. 135-136). }\end{array}$ \\
\hline $\begin{array}{l}\text { Ballard and } \\
\text { Howell (1998) }\end{array}$ & $\begin{array}{l}\text { "Value is generated through a process of negotiation between customer } \\
\text { ends and means" (p. 5). }\end{array}$ \\
\hline Koskela (2000) & Fulfilment of customer requirements. \\
\hline $\begin{array}{l}\text { Womack and } \\
\text { Jones (2003) }\end{array}$ & $\begin{array}{l}\text { "[A] capability provided to a customer at the right time and at an } \\
\text { appropriate price, as defined in each case by the customer" (p. 353). }\end{array}$ \\
\hline $\begin{array}{l}\text { Emmitt et al. } \\
\qquad(2005)\end{array}$ & $\begin{array}{c}\text { "[O]utput of the collective efforts of the parties contributing to the design } \\
\text { and construction process; central to all productivity; and providing a } \\
\text { comprehensive framework in which to work" (p. 59). }\end{array}$ \\
\hline $\begin{array}{l}\text { Drevland and } \\
\text { Lohne (2015) }\end{array}$ & $\begin{array}{c}\text { "Value is a result of an evaluative judgment. This judgment is guided by } \\
\text { values and based on the evaluator's knowledge at hand. It is always } \\
\text { based upon comparing two or more alternatives in a given context. This } \\
\text { context envelops all get and give consequences for a particular party from } \\
\text { a decision made on the basis of the value judgment. The get and give } \\
\text { consequences are always in the form of gained or lost experiences, or } \\
\text { expressed in monetary terms as a placeholder for experiences. The } \\
\text { consequences are not summative, the value judgment is done by } \\
\text { considering them all at once" (pp. 480-481). }\end{array}$ \\
\hline $\begin{array}{l}\text { Institute of Value } \\
\text { Management UK } \\
\text { (2020) }\end{array}$ & $\begin{array}{l}\text { "The concept of value is based on the relationship between satisfying } \\
\text { needs and expectations and the resources required to achieve them." }\end{array}$ \\
\hline
\end{tabular}

In contrast, "goals are guides for action" (Widmeyer and Ducharme 1997, p. 102). They represent performance levels that need to be achieved within a certain time (Latham and Locke 2006) and help project teams to see "if things are going in the right direction" (Schöttle and Tillmann 2018, p. 439). Criteria are decision rules or guidelines (Suhr 1999). Thus, goals are the result of values and goals shape our criteria (see Figure 1). Consequently, values impact the decision-making process (Suhr 1999), because values drive the decision-making criteria (Kahneman and Tversky 1984).

For example, when choosing a light bulb for a living room, one of the values of the decision-maker could be being environmentally friendly and therefore saving energy is very important. Based on these values, a goal of the decision-maker could be a reduced environmental impact by $50 \%$ by next year. The criteria to distinguish between the attributes of alternatives within the factor energy efficiency would be less lumens/watts is better. The value would be the outcome of what the light bulb provides in comparison to the other alternatives. 


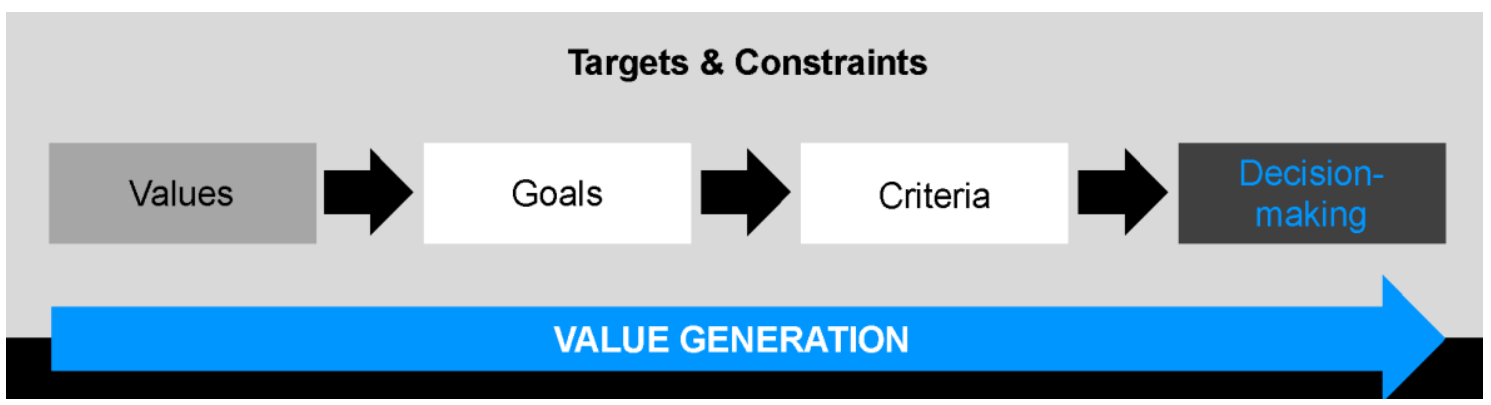

Figure 1: Values drive decision-making

\section{STRATEGIES TO GENERATE VALUE}

The perception of value deriving from value management theory has historically been the center of value perception. Here, two major strategies exist in construction to generate value, value management (VM) and target value delivery (TVD). Value Management (VM) stems back to system-thinking in design and Value Engineering in the 1960s (Green 1994). Value Management is a process aiming to provide optimal project outcomes whilst remaining focused on time, cost and quality constraints (Institute of Value Management UK 2020). The optimal project outcome is here understood as a product living up to defined functions delivered by using minimum resources (Bird et al. 2001; Green 1994). Thus, the purpose of VM is to control the value generation (Emmitt et al. 2005). VM consists of several acknowledged tools to define value such as functional analysis, brainstorming to identify potential improvements and weight those against the agreed functions or enhancing communication through workshops. Many of these tools could be compared to decision methods such as Weighting Rating and Calculation (WRC) as main functions get rated prior to discussions of context. When a product or service is drafted or designed, VM tools can be applied to assess potential optimizations leading to an iteration of the design process. There is no illusion that one optimal solution exists, but, by establishing a common decision framework, participants can think and communicate potential improvement ideas (Green 1994). In cases where interventions are held on a regular basis with the right facilitation, these conversations support the realization of the customers' goals for the production (Koskela 2000; Shen and Guiwen 2003) and the value system (Wandahl 2005). Value Management can therefore reconcile all stakeholders' perspectives to balance out satisfied needs and resources (Institute of Value Management UK 2020). As Emmitt (2005) points out: "the difficulty with the value management approach is that the workshops are promoted as something additional to the management of process, a tool to enhance value in design management [...] rather than value as an integral element of professional design management" (p. 3). Moreover, VM is usually limited to the design phase.

Target Value Design (TVD) is a management practice that was first successfully applied in construction in 2002 (Ballard and Reiser 2004). Subsequently, target value design began to be used to name target costing in construction (Tillmann et al. 2017) that was developed by Toyota (Feil et al. 2004). Within the last decade, the perspective of designing to target costing has become broader, and thus the term target value design has changed to target value delivery. The change of the term can be explained by defining the difference within value design and value delivery. Based on Emmitt et al. (2005), value design is the understanding and development of value, whereby value delivery is the transformation of the value design into a product design and the product itself. TVD 
focuses intensively on the customer value of all project phases (Zimina et al. 2012), which is different from the cost to acquire a product (Ballard 2012). However, in theory and practice very few examples exist on how to define value as a first step of TVD.

Yet, TVD and VM emerged from different approaches. The background of TVD is target costing, whereby the background of VM is to control value while reducing the cost. TVD is a holistic approach that consists of value design and value delivery through all project phases. In comparison, VM focuses especially on the early design stage. Where Value Management stems from system thinking (Green 1994), TVD is more process based, which takes the dynamic of values into account. Nevertheless, VM holds some tools and techniques to engage with engineering disciplines when defining the customer's value paradigm. Thus, TVD and VM in many ways overlap.

\section{CBA FOR ASSESSING VALUE IN DECISION-MAKING}

This section introduces the CBA process according to Suhr (1999), why cost and value are separated in CBA analysis, and how CBA helps assess value based on the customer's values.

\section{CBA PROCESS}

CBA is a system for making decisions based on the importance of beneficial differences (advantages) between alternatives. It has definitions, models, principles and a set of methods (Suhr 1999). The CBA system divides the decision-making process into five phases (Suhr 1999): (I) the stage-setting phase, (II) the innovation phase, (III) the decision-making phase, (IV) the reconsideration phase, and (V) the implementation phase.

- During the stage-setting phase (I), decision-makers determine the purpose, scope and circumstances of the decision; discover the concerns of the stakeholders; identify the needs and preferences of the stakeholders; begin establishing 'must' and 'want' criteria; and identify every participant who will be involved in the decision. In addition, during this stage, leaders should ensure that the team possesses the skills necessary to successfully carry out the process of CBA.

- During the innovation phase (II), decision-makers ensure that CBA training has been adequately provided; formulate alternatives (we cannot choose the best alternative if we do not formulate it); and determine and display attributes related to each alternative (it may take days, weeks, or years).

- During the decision-making phase (III), decision-makers summarize the attributes, determine the advantages, and decide the importance of each advantage. This is an assessment of value, which is typically subjective as each person interprets the decision differently. Decision-makers also evaluate costs during this phase.

- During the reconsideration phase (IV), decision-makers reconsider the decision by answering questions such as 'Can the decision be improved?', 'Are there other alternatives to consider?' and 'Are there other relevant factors to consider?', and by reviewing information from the three previous phases.

- Finally, during the implementation phase (V), decision-makers establish and carry out an implementation plan based on their decision. Decision-makers commit to moving forward together and doing their part to have a successful implementation. 
CBA can support the value delivery process especially in phase (I). Although Suhr (1999) does not specify how to define value, based on lean literature we can define value as the output guided by values that are expressed in goals. Based on this cause-effect relationship the decision-making process generates value. Thus, understanding the values of the customer and creating an aligned system of values is necessary to drive value in the decision-making process. (Figure 2 shows the phases of the CBA system to generate value.) Then, during the first two phases, Design Thinking (DT) as a stepwise and iterative user problem-solving approach can be used to identify value and collect data and information from the relevant participants (Brown 2008; Kelley and Kelley 2013) to structure them into factors and criteria for phase (III). During the reconsideration phase, value engineering (VE) can be applied (Suhr 1999) to improve the outcome. Thus, CBA is a decision-making method which is value driven. When applying CBA, the decisionmaking group will need to clarify the value expressed in the beneficial difference (advantages) between the alternatives. Based on Holbrook (1999), we can state that CBA helps to make a better evaluative judgement because value gets discussed based on the transparent documentation of the criteria. Furthermore, to follow the stages, decisionmakers have to understand the customer values in depth in order to reach a decision.

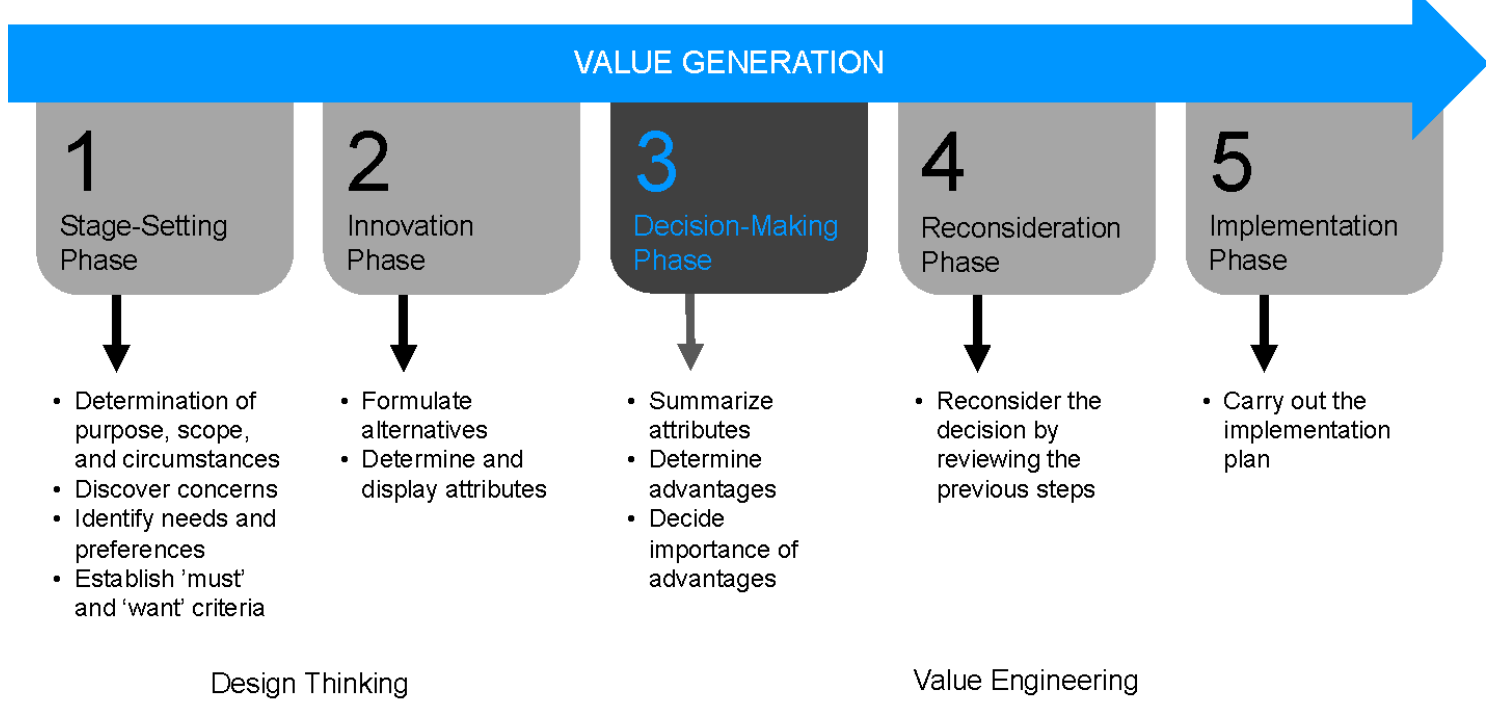

Figure 2: CBA system to generate value during decision-making

\section{VALUE VS. COST-DRIVEN DECISION}

When project teams use traditional decision-making methods such as Weighting Rating and Calculating (WRC) or the weighted sum of 'value' and consider cost as a value, they tend to weight cost very high, which obscures any difference in actual value in the decision-making process. Correa et al. (2017) demonstrate how inefficient it is to weight cost heavily when using WRC, and how it leads the team to choose suboptimal alternatives where better alternatives can be found for the same or lower cost.

Moreover, Arroyo et al. (2013), Kpamma et al. (2016), and Schöttle and Arroyo (2017) show clearly the importance of not building a value and cost ratio, because, when offsetting value and cost, cost is usually driving the decision. Lean Thinking focuses on the value generation. Therefore, decisions should be made based on value and by considering cost as a requirement and not as a driver. Suhr (1999) has already defined cost as a medium of exchange that needs to be displayed across value. By doing so, the decision-making group can decide if it is worth paying more in order to realize an 
alternative that contains more advantages or not. The team can now have a real conversation about the alternatives and is not biased by money (Arroyo et al. 2014).

\section{HOW CBA HELPS ASSESS VALUE BASED ON VALUES}

The construction industry is a product-focused industry, where it can be difficult to frontload resources for the early phases of value definition. Moreover, to identify the more significant decisions across a project team it is necessary to have a shared understanding of the customer's values, e.g. by having a cross-disciplinary discussion of values. Therefore, referring to the design phase, Schöttle et al. (2018) found out that the decisionmaking and the related governance process need to be clearly structured. They also recommend implementing an integrated bottom-up process for decision approval. Those defined processes need to be developed not only for the design phase; they need to be built throughout the whole project delivery system. In addition, Koskela et al. (2018) proposed designing as a court of law, where there is a fair trial process, all parts are heard, and design decisions are based on fact finding and transparent documentation. Having a set structure, CBA helps to deliver meaningful discussions around decision-making and value while separating value from cost. By doing so, CBA drives the understanding of the customer's values as participants develop a common understanding regarding values, context, and constraints. This is the big difference to VM and explains the match of CBA and TVD. Where VM looks at value as a defined measure, value seen in the context of CBA serves more as a tool to iteratively refine and decide on the customer's value propositions.

However, several examples exist where value identification and decision-making connect to values in a non-obvious way. Here, three types of situations that can happen when teams use CBA as a decision-making method are presented:

- Alternatives differentiate based on a criterion that is of value for the customer. For example, a big advantage in energy efficiency when choosing a lighting system for a net zero energy (NZE) building (Arroyo 2014).

- Alternatives differentiate based on a criterion that is not of value for the customer. For example, a big noise difference in a highly frequented area between different HVAC systems may not be valued at all (Arroyo et al. 2016a).

- Alternatives do not differentiate based on a criterion that is of value for the customer. For example, when choosing a ceiling tile one of the architects cared about $\mathrm{CO}_{2}$ emissions, and sustainability was a value for the project, but it did not matter because it did not provide a difference between the attributes of the alternatives (Arroyo et al. 2016b).

Thus, you can still have value but not make decisions following them. Project teams can also use CBA without defined values or without being collaborative, but that is not the nature and purpose of the method. CBA demands the incorporation of stakeholders and clear defined values to analyze the value of the decisions based on a particular context.

\section{CONCLUSIONS}

This paper explored the impact of values on decisions and how CBA can help in delivering value when making decisions by reviewing the literature. Therefore, we defined the following research question: How does Choosing by Advantages (CBA) support making deliberate decisions based on values and thereby help to deliver value for a project? We state that CBA offers a systematic process by which the value of the 
customer can be translated into decisions and dilemmas. Hereby, value is not a static measurement as it can be further developed and refined. Furthermore, we demonstrate the importance of understanding the customer's values, because values drive and direct every decision and often unconsciously. Values are the basis of every goal, resulting in criteria to decide between attributes of alternatives within a factor. By better understanding the values of the customer, goals that direct the decision-making process to generate value can be more easily set.

Nevertheless, the purpose of this paper was to better understand how value drives decision-making from a theoretical point of view. Practically, research is needed to obtain better knowledge about the underlying values of the customer in the context of value generation.

\section{REFERENCES}

Arroyo, P. 2014. Exploring decision-making methods for sustainable design in commercial buildings. PhD Diss., UC Berkeley, California, USA.

Arroyo, P., Ballard, G., and Tommelein, I. D. 2014. "Choosing by advantages and rhetoric in building design: Relationship and potential synergies." Proc. $22^{\text {nd }}$ Ann. Conf. Int. Group for Lean Construction, 1(510), 391-408.

Arroyo, P., Tommelein, I., and Ballard, G. 2013. "Using 'choosing by advantages' to select ceiling tile from a global sustainable perspective." Proc. $21^{\text {st }}$ Ann. Conf. Int. Group for Lean Construction Fortaleza, Brazil 1(510), 309-318.

Arroyo, P., Tommelein, I. D., and Ballard, G. 2016a. "Selecting globally sustainable materials: A case study using choosing by advantages." Journal of Construction Engineering and Management, 142(2), 1-10.

Arroyo, P., Tommelein, I. D., Ballard, G., and Rumsey, P. 2016b. "Choosing by advantages: A case study for selecting an HVAC system for a net zero energy museum." Energy and Buildings, Elsevier B.V., 111, 26-36.

Ballard, G. 2012. "Should project budgets be based on worth or cost?" IGLC 2012 - 20th Conference of the International Group for Lean Construction.

Ballard, G., and Howell, G. (1998). "What kind of production is construction?" Proc. $6^{\text {th }}$ Ann. Conf. Int. Group for Lean Construction, Guaruja, Brazil, 13-15 August, 1-15.

Ballard, G., and Reiser, P. 2004. "The St. Olaf College Fieldhouse Project: A case study in designing to target cost." Proc. $12^{\text {th }}$ Ann. Conf. Int. Group for Lean Construction, Helsingør, Denmark, 234-249.

Bird, S., Potter, J. E., Hiller, D. M., and Bowers, K. H. 2001. Value Management for tunnel procedures. TRL report 448.

Brown, T. (2008). "Design thinking." Harvard Business Review, 86(6), 84-92.

Christoffersen, A. K. 2003. State-of-the-Art Rapport. Arbejdsgruppe Værdiledelse (State of the Art Report: Working Group Value Management). Byggeriets Evaluerings Center, August.

Correa, M. G., Arroyo, P., Mourgues, C., and Flager, F. 2017. "Comparing choosing by advantages and weighting, rating and calculating results in large design spaces." Proc. $25^{\text {th }}$ Ann. Conf. Int. Group for Lean Construction, Heraklion, Greece, 259-266.

Drevland, F., and Klakegg, O. J. (2019). "Developing a conceptual model for value delivery in value shop configured construction projects." Proc. $27^{\text {th }}$ Ann. Conf. Int. Group for Lean Construction, Dublin, Ireland, 1391-1402.

Drevland, F., and Lohne, J. (2015). "Nine tenets on the nature of value." Proc. $23^{\text {rd }}$ Ann. Conf. Int. Group for Lean Construction, Perth, Australia, 475-485. 
Emmitt, S., Sander, D., and Christoffersen, A. K. 2005 "The value universe: Defining a value based approach to lean construction." Proc. $13^{\text {th }}$ Ann. Conf. Int. Group for Lean Construction, Sydney, 57-64.

Feil, P., Yook, K., and Kim, I. 2004. "Japanese target costing: a historical perspective." International Journal of Strategic Cost Management, 10-19.

Green, S. D. 1994. "Beyond value engineering: smart value management for building projects." International Journal of Project Management, 12(1), 49-56.

Holbrook, M. B. 1999. "Introduction to consumer value". In: Consumer Value: A Framework for Analysis and Research. London, UK: Routledge.

Institute of Value Management UK. 2020. "What is value management?" $<$ https://ivm.org.uk/what-is-value-management $>$ (Jan. 3, 2020).

Johnson, H. T., and Kaplan, R. S. 1987. Relevance lost-the rise and fall of Management Accounting. Boston, MA: The Business School Press.

Kahneman, D., and Tversky, A. 1984. "Choices, values, and frames." American Psychologist, 39, 341-350.

Kelley, T., and Kelley, D. (2013). Creative confidence: Unleashing the creative potential within us all. New York, NY: Crown Business.

Koskela, L. (2000). An exploration towards a production theory and its application to construction. VTT Publications 408, Finland.

Koskela, L., Arroyo, P., and Ballard, G. 2018. "Designing as a court of law." Proc. $26^{\text {th }}$ Ann. Conf. Int. Group for Lean Construction, Chennai, India, 614-624.

Kpamma, Z. E., Adinyira, E., Ayarkwa, J., and Adjei-Kumi, T. 2016. "Application of the CBA decision system to manage user preferences in the design process." Journal of Professional Issues in Engineering Education and Practice, 142(1), 10.1061/(ASCE)EI.1943-5541.0000258.

Latham, G. P., and Locke, E. A. 2006. "Enhancing the benefits and overcoming the pitfalls of goal setting." Organizational Dynamics, 35(4), 332-340.

Salvatierra-Garrido, J., Pasquire, C., and Thorpe, T. 2010. "Critical review of the concept of value in lean construction theory." In: Walsh, K. and Alves, T., Proc. $18^{\text {th }}$ Ann. Conf. Int. Group for Lean Construction, Haifa, Israel, 14-16 July, pp. 33-41.

Schöttle, A., and Arroyo, P. 2017. "Comparison of Weighting-Rating-Calculating, Best Value, and Choosing by Advantages for Bidder Selection." Journal of Construction Engineering and Management, 143(8), 10.1061/(ASCE)CO.1943-7862.0001342.

Schöttle, A., Arroyo, P., and Bade, M. (2015). "Comparing three methods in the tendering procedure to select the project team." Proc. 23 ${ }^{\text {rd }}$ Ann. Conf. Int. Group for Lean Construction, O. Seppänen, V. González, and P. Arroyo, eds., Perth, Australia, 267276.

Schöttle, A., Arroyo, P., and Christensen, R. 2018. "Demonstrating the value of an effective collaborative decision-making process in the design phase." Proc. $26^{\text {th }}$ Ann. Conf. Int. Group for Lean Construction, Chennai, India, 2, 899-909.

Schöttle, A., and Tillmann, P. A. (2018). "Explaining the benefits of team goals to support collaboration." Proc. 26 ${ }^{\text {th }}$ Ann. Conf. Int. Group for Lean Construction, Chennai, India, 432-441.

Schwartz, S.H., and Bilsky, W. (1987). "Toward a universal psychological structure of human values.” Journal of Personality and Social Psychology, 53(3), 550-562.

Shen, Q., and Guiwen, L. 2003. "Critical success factors for value management studies in construction." Journal of Construction Engineering and Management, 129(5), 10.1061/(ASCE)0733-9364(2003)129:5(485). 
Suhr, J. (1999). The choosing by advantages decisionmaking system. Westport, CT: Quorum.

Tillmann, P. A., Do, D., and Ballard, G. 2017. "A case study on the success factors of target value design." Proc. 25 $5^{\text {th }}$ Ann. Conf. Int. Group for Lean Construction, Heraklion, Greece, 563-570.

Wandahl, S. (2005). Value in building. PhD thesis, Aalborg University, Denmark.

Widmeyer, W. N., and Ducharme, K. 1997. "Team building through team goal setting." Journal of Applied Sport Psychology, 9(1), 97-113.

Womack, J. P., and Jones, D. T. 2003. Lean thinking: Banish waste and create wealth in your corporation. London, UK: Simon \& Schuster.

Zimina, D., Ballard, G., and Pasquire, C. 2012. "Target value design: Using collaboration and a lean approach to reduce construction cost." Construction Management and Economics, 30(5), 383-398. 